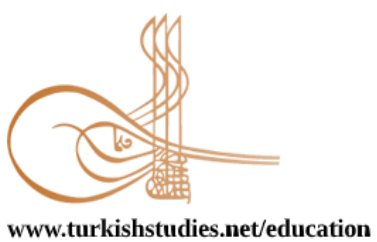

www.turkishstudies.net/education
Turkish Studies - Educational Sciences

eISSN: 2667-5609

Research Article / Araştırma Makalesi

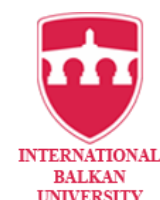

BALKAN
UNIVERSITY

Sponsored by IBU

\title{
Kültürrlerarası İletişim Kaygısının Üniversite Öğrencilerinin Yabancı Dil Öğrenimi Üzerindeki Etkisi
}

\author{
The Effect of Intercultural Communication Apprehension on University Students' Foreign \\ Language Learning
}

\author{
Kenan Demir*
}

\begin{abstract}
Because of improving technology, intercultural communication has become a more apparent part of human life. Especially in foreign language learning, interacting directly or via online media with people speaking the target language has emerged as a result of the opportunities provided by the technology. This interaction is provided through English, which has become a global common language in real sense since the second half of the $20^{\text {th }}$ century. To express more clearly, use of English as a Lingua Franca meaning the common language has become both target and catalyst of intercultural communication. Thus; it may be assumed that apprehension which is possible to occur in this communication process may affect intercultural communication and accordingly the learning of the target language negatively. The purpose of this article is to measure the effect of intercultural communication apprehension on foreign language learning among university students through Intercultural Communication Apprehension Scale. The scale of the survey measures people's intercultural communication apprehension in three levels which are low, medium and high. Moreover, the potential relation between subjects' descriptive information such as abroad experience and gender and their intercultural communication apprehension has been analyzed. All of the subjects of the survey are students from Kocaeli University, learning English at a language school at the center of Kocaeli Province and official permission is taken from the board of university for the study. It is assumed that low intercultural communication apprehension may enhance students' interaction with the target language speaker and make foreign language learning more efficient.
\end{abstract}

Structured Abstract: Introduction: Whether native or foreign, the purpose of language learning is to communicate. Apprehension is one of the factors that are thought to affect this process. In this sense, this study aims to assess the effect of intercultural communication apprehension on university students' foreign language learning. For this purpose, answers to the following questions are sought: Is there a relation between foreign language learning and intercultural communication apprehension? Are other demographic factors such as gender and previous experience of abroad effective on intercultural communication apprehension? What are the potential ways to decrease possible negativity of this apprehension on foreign language learning? In order to answer aforementioned questions a scale developed by Neuliep and

\footnotetext{
* Doktora Öğrencisi, Kocaeli Üniversitesi, İletişim Fakültesi, İletişim Bilimleri Bölümü PhD Student, Kocaeli University, Faculty of Communication, Department of Communicational Sciences ORCID0000-0001-8314-6475

kenandmr06@hotmail.com
}

Cite as/ Atıf: Demir, K. (2020). Kültürlerarası iletişim kaygısının üniversite öğrencilerinin yabancı dil öğrenimi üzerindeki etkisi. Turkish Studies - Education, 15(4), 2531-2548. https://dx.doi.org/10.47423/TurkishStudies.43187

Received/Geliş: 27 April/Nisan 2020

Accepted/Kabul: 27 August/Ağustos 2020

Copyright (C) INTAC LTD, Turkey 
McCroskey (1997), and a personal information form are applied to 140 Kocaeli University students. As a result, intercultural communication apprehension of the subjects is evaluated. In addition, via some cross references possible relations between intercultural communication apprehension and some demographic qualities are analyzed some of which show compatible results with the hypothesis of the study.

\section{Literature Review}

Today, English is 'the Lingua Franca' of the world with its millions of speakers. Moreover, many more people are trying to learn it for various reasons ranging from career prospects to education. However, the relation between language and culture makes it paramount to take culture's effect on language into consideration. Myron and Koester (2008: 25) refer to Kluckholn's (1952) more than two hundred definitions of culture, and state that it is impossible to reach a unique definition of it. Nevertheless, Kartarı (2014: 15) give an inclusive definition by saying that "Culture is anything and everything compassing human life except the ones given by the nature." Jiang (2000: 328) describes the relation betwee'n language and culture as follows: "Without culture, language would die, and without language, culture would lose its formation." To be more specific, culture creates the context in which the words of a language make sense. Therefore, when learning a foreign language, it is vital to consider cultural aspects. Liddicoat (2003), Byram (1997), Hymes (1962), and Kramsch (1993) also express the importance of culture and language relation. Therefore, it is possible to say that both native and target languages' cultures influence how we understand the symbols of a given language as at the core, language learning is an intercultural communication. 'Intercultural communicative ability' that may be referred as the ability to adopt to the requirements of a different culture or the ability to communicate people from a different culture is another significant term about foreign language learning (Samovar, Porter and McDaniel, 2010; Gardner, 1963; Bennet, 2009; Byram, 2008). Accordingly, it is posited that factors such as apprehension, prejudice and stereotyping may harm intercultural communication (Levine and McCroskey, 1990; Lustig and Andersen, 1991; Payne and Richmond, 1984). Especially, apprehension is a major block in the process of communication. Therefore, it is highly significant to measure the effect of it. This study aims to evaluate the effect of intercultural communication apprehension and some other demographic factors on university students' foreign language learning.

\section{Method}

In the study 'exception method' is used. This method is vastly used in educational sciences and seeks to find the answer to the questions of 'why' and 'how'. In this method researchers make a deep research keeping away from prejudices. Generally, survey types are utilized to collect data (Ekiz, 2013). In our study a Likert type scale developed by Neuliep and McCroskey (1997) and adapted to Turkish by Türkoğlu (2018) is used. This scale composes of 14 factors, the scores of which are assessed according to formula given. The subjects are 140 Kocaeli University students aged 19 to 23 who learn English at a language school in the province of Kocaeli.

\section{Discussion, Conclusion and Suggestions}

The results of the study on the effect of intercultural communication apprehension on university students' foreign language learning show that majority of the students show either mid or high level of apprehension which is compatible with studies of Ewald (2007), Gregersen (2003), Sparks \& Ganschow (2007), Spielmann \& Radnofsky (2001), Young (1999), (cited by Hamamc1, 2015). Another result of the study shows that women have higher level of intercultural communication apprehension than men. Other studies regarding the same relation show discordant results (Aydın \& Takkaç, 2007; cited by Hamamc1, 2015). Students with previous language learning experiences such as having been abroad or studying another foreign language show different levels of intercultural communication apprehension which reveals that there is no significant relation between these factors and intercultural communication apprehension.

As Rafek et al. (2013: 92) report, the higher the intercultural communication apprehension, the more negatively the students' communication process is affected. Therefore, in the process of foreign language 
learning, the effect of intercultural communication apprehension is to be taken into account. So, correct strategies are to be utilized to minimize the cultural blocks in the process of foreign language learning. To reduce students' intercultural communication apprehension, first of all, similarities between target and source cultures should be emphasized; the differences should be taken to the second plan. Moreover, it should be emphasized that the target language is only a communication tool; it should be stated that this situation is not an intercultural reason for superiority. It should be noted that both languages and both cultures are valuable. Today, the increasing spread of Anglo-Saxon culture due to globalization is an advantage in terms of teaching English. However, it should be noted that the source culture is equally valuable and unique, which can be a useful tool to reduce intercultural communication apprehension of the students.

Keywords: Foreign Language Teaching, Intercultural Communication, Apprehension, University Student, Communicative Competence.

Öz: Kültürlerarası iletişim gelişen teknoloji ile birlikte insan hayatının daha görünür bir öğesi haline gelmiştir. Özellikle yabancı dil öğreniminde doğrudan hedef dili konuşan bireylerle yüz yüze ya da çevrimiçi araçlar vasıtasıyla etkileşime geçmek teknolojinin sunduğu imkânların bir sonucu olarak ortaya çıkmıştır. Bu etkileşim 20. Yüzyılın ikinci yarısından itibaren tam anlamıyla küresel ortak dil haline gelen İngilizce öncülüğünde sağlanmaktadır. Daha açık bir ifadeyle, İngilizcenin ortak dil anlamına gelen Lingua Franca olarak kullanımı kültürlerarası iletişimin hem amacı hem de katalizörü olmuştur. Bu iletişim sürecinde yaşanması olası kaygının kültürlerarası iletişimi, dolayısıyla da hedef dili öğrenmeyi olumsuz etkileyeceği var sayılabilir. Bu makalenin amacı üniversite öğrencileri arasında yabancı dil öğreniminde kültürlerarası iletişim kaygısının etkisini ölçmektir. Bu maksatla daha önce Türkçeye uyarlanan 'Kültürlerarası İletişim Kaygısı Ölçeği' kullanılmıştır ve çalışma için gerekli etik kurulu onayı alınmıştır. Ölçek; bireylerin kültürlerarası iletişimsel kaygı düzeylerini düşük, orta ve yüksek olmak üzere üç seviyede incelemektedir. Ayrıca katılımcıların yurt dışı tecrübesi ve cinsiyet gibi çeşitli tanımlayıcı bilgileri ile kültürlerarası iletişim kaygıları arasındaki olası ilişki de araştırılmıştır. Ölçeğin uygulandığı bireylerin tamamı Kocaeli İl merkezindeki bir yabanc1 dil okulunda İngilizce öğrenen Kocaeli Üniversitesi öğrencileridir. Düşük kültürlerarası iletişim kaygısının öğrencilerin hedef dil konuşucusu ile etkileşimini artıracağı ve dolayısıyla yabancı dil öğrenimini daha verimli kılacağı ön görülmektedir.

Anahtar Kelimeler: Yabancı Dil Öğretimi, Kültürlerarası İletişim, Kaygı, Üniversite Öğrencisi, İletişimsel Yeti.

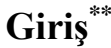

İletişim sadece belirli bir dili konuşan grup üyeleri arasında gerçekleşmez; aynı zamanda farklı dilleri konuşan toplumlar da ticaret, eğitim, seyahat, savaş gibi çeşitli nedenlerden ötürü birbirleriyle iletişim kurarlar. Bu iletişimin aracı ya iletişimin taraflarından birinin dili ya da Lingua Franca olarak adlandırılan yaygın üçüncü bir dil olabilir. Günümüzde bilindiği üzere İngilizce yüz milyonları aşan konuşanıyla dünyanın ortak dili konumundadır. Ayrıca küreselleşme ile ülkeler arasındaki fiziki sınırların geçerliliğini yitirdiği görülürken internet, neredeyse tüm dünya uluslarını sanal olarak bir araya getirmiştir. Tüm bu etmenler toplumlar arasındaki iletişimi daha etkin hale getirirken bir Lingua Franca olarak İngilizce öğrenimine olan talebi de artırmıştır. Kültürün dil üzerindeki yadsınamaz etkisini dikkate aldığımız zaman yabancı dil öğreniminde kültürel öğelerin ne kadar etkili olduğu anlaşılabilir. Jiang (2000: 328) dil ile kültür arasındaki ilişkiyi organik bir bakış açısıyla şu şekilde açıklar: "Kültür olmazsa dil ölür; dil olmazsa, kültür şeklini kaybeder.

\footnotetext{
** Bu çalışma bağlamında yararlanılan birçok yabanc1 kaynakta öğretim (teaching) ve öğrenim (learning) kavramları birbirini karşılayacak şekilde kullanılmıştır. Bu nedenle çalışmada her iki kavram da yabancı dil edinim sürecini anlatmak için kullanılmıştır.
}

Turkish Studies - Education, 15(4) 
Daha açık bir ifadeyle; kültür bir canlının yaşamsal döngüsü olan kan kadar elzemdir; ama dil olmaksızın kültür hiçbir şey ifade etmez ve kültürün önemi yok olur. Öte yandan kültür olmaksızın dil yaşayamaz ölür."

Özellikle yabancı dil öğrencilerinin hedef dili konuşan kişilerle doğrudan iletişime geçmesi kültürün dil üzerindeki etkisini göstermek bakımından önemlidir. Çünkü kültür bizim uyaranları anlamlandırma rehberimizdir. Benzer bir ifadeyle iletişim sürecinde neyi, nasıl anlayacağımızı belirleyen bağlamsallık ve kültürdür. Sonuç olarak; kültürlerarası iletişim yabancı dil öğrenim sürecini temelden etkileyen bir etmendir. Bu nedenle kültürlerarası iletişim kaygısının bu süreci etkileyebileceği ön görülmektedir. Çalıșmamızın analiz çerçevesi yabancı dil öğrencilerinin kültürlerarası iletișimsel kaygılarını ölçme amacı taşımaktadır. İletișim kaygısının öğrencilerin yabanc1 dil öğrenimi üzerindeki etkisi konusundaki görüşleri Rafek vd. (2013: 92) şu şekilde aktarmışlardır: "Bu duygunun fazlalığı bazı insanların sözlü iletişim sırasında korkmasına ve iletişimden kaçınmasına neden olur (Daly, 1991: 3). Ayrıca Mejiaset (1991) yüksek iletişim kaygısı olan bireylerin derslerde sözlü üretimlerini sınırladığını ve sessiz kalmayı tercih ettiğini ortaya koymuştur.” Bu bağlamda çalışmamızda öncelikle dil ile kültür arasındaki ilişki irdelenecek, daha sonra kültür ve yabancı dil öğretimi arasındaki ilişki açıklanacak ve ardından da kültürlerarası iletişimin önündeki engeller incelenecektir. Uygulama bölümünde ise Neuliep ve McCroskey (1997) tarafindan geliştirilen ve Türkoğlu (2018) tarafindan Türkçeye uyarlanan kültürlerarası İletişim Kaygısı Ölçeği kullanılarak Kocaeli İl Merkezi'nde bulunan bir yabancı dil okulunda İngilizce eğitimi alan Kocaeli Üniversitesi öğrencilerinin kültürlerarası iletişim kaygıları ölçülecektir.

\section{Dil Kültür İlişkisi}

Kültür kavramı dil başta olmak üzere insanla ilgili her tür olguyu kuşatmış olsa da kültürün ne olduğu ya da ne olmadığı konusunda üzerinde anlaşılmış bir tanımı yoktur. Myron ve Koester (2008: 25), Kroeber ve Kluckhohn'un (1952) kültür kavramına ilişkin iki yüz sayfayı aşan çeşitli tanımları içeren çalışmalarını işaret ederek kültür konusunda ortak bir tanıma ulaşmanın imkansız olduğunu vurgular. Bununla birlikte Kartarı'nın (2014: 15) tanımı kapsam bakımından dikkat çekicidir:

Kültür, bireyin gündelik yaşamını etkileyen ve doğanın verdikleri dışında kalan her şeyi kapsayan, soyut ve somut her türlü insan ürününü içeren bir çatı kavramdır. Kültür; göreceli olarak büyük bir insan grubunun davranışlarını etkileyen inançlar, değerler, normlar hakkındaki öğrenilmiş ortak yorumların bütünüdür.

Diğer taraftan, çalışmamızın içeriği açısından aşağıdaki kültür tanımları da açıklayıcıdır. "Kültür bireyin kendisi ve diğerleri hakkındaki algıların içeren sosyal bir yapıdır." (Kramsch, 1993: 5). Fiske'e (2003: 158) göre ise "Kültür bir anlam yaratma sürecidir, hem dışsal doğayı ve gerçekliği hem de onun bir parçası olan toplumsal sistemi ve bu sistem içindeki insanların toplumsal kimliklerini ve gündelik etkinliklerini anlamlandırır." Liddicoat da (2002) benzer şekilde kültürün toplumsal yönünü vurgular ve kültürün tekrar tekrar kurgulandığını, göreceli olduğunu, bireyin dünyaya ilişkin düşünme pratiklerini şekillendirdiğini, dolayısıyla da davranışlarımızın kültürün bir sonucu olduğunu belirtir. $\mathrm{Bu}$ tanımların dışında Jackson (2012) dil ile kültür arasındaki ilişkiyi/bağımlılığı şöyle ifade eder:

Bütün diller insan deneyimlerini farklı şekilde kodlar. Daha açık bir ifadeyle insan deneyimleri bütün dillerde yapı, hiyerarşi ve sosyal özellikleri bakımından farklı şekillerde kodlanır. Böylece her çocuk dil aracılığıyla içinde yetiştiği külttürün özelliklerine göre sosyalleşir. Diğer taraftan tüm diller düşüncelerin belirli bir şekilde gelişmesine imkan tanıdıkları için o dilin kültürel penceresinden bakan bireyler bir başka dilin kalıtsal kültürel kodlarını anlayamayabilir. Sonuç olarak; belirli bir dil 
(anadilimiz) tüm hayatımız boyunca bize kusursuz bir şekilde hizmet etse de aynı dünyaya farklı bir pencereden bakmamızın önündeki en büyük engele dönüşebilir.

Kültür ile dil arasındaki ilişki Hsin (2000: 329) tarafından aşağıdaki gibi aktarılır:

Dil ve kültür birbirine öyle yakındır ki eş anlamlı olarak tanımlanırlar (Scarcella, Oxford, 1992). Bir taraftan dil insanların kültürel düşüncelerini, inançlarını ifade etmek ve iletişim kurmak için kullanılır. Diğer taraftan kültür dilde yerleşiktir. Dil ile kültür arasındaki bu girift ilişki Brown tarafından (200: 177) şu cümle ile özetlenir: "Dil kültürün bir parçasıdır ve kültür de dilin bir parçasıdır; bu iki öğe birbirine öyle yakından bağlıdır ki ya kültürün ya da dilin önemini kaybetmeksizin ayrılmaları mümkün değildir."

Yukarıdaki açıklamalardan da anlaşılacağı üzere dil ile kültür birbirinden bağımsız kavramlar değildir. Kültür dili yaratır, dil de kültürün sonraki kuşaklara aktarılmasını sağlar.

\title{
Kültür ve Yabancı Dil Öğretimi
}

Liddicoat (2003), Byram (1997), Hymes (1962), Kramsch (1993) gibi birçok araştırmacı yabanc1 dil öğretiminde kültürel öğelerin hesaba katılmasının önemini vurgulamıştır. Buna ek olarak Arabski ve Wojtaszek'in (2011: 1-2) yabanc1 dil ediniminin sosyolinguistik bir süreç olduğunu ve kültürle ilgili dışsal öğeleri içerdiğini vurgular. Benzer bir ifadeyle yabancı bir dil öğrenimi hedef ve kaynak kültürlerin etkisinden bağımsız gerçekleşen bir süreç değildir. Her ne kadar öğretilmesi gereken bu kültürün içeriği hakkında farklı bakış açıları olsa da bu durum çalışmamızın bağlamı dışında kalmaktadır. Bununla birlikte yabancı dil öğretiminde niçin kültürel öğelerin bulunması gerektiğini Hsin (2000: 328) aşağıdaki gibi özetler:

\begin{abstract}
Yabancı dil öğrencisinin dil öğrenmekteki amacı ya o dili ana dili olarak konuşanlarla ya da kendisi gibi ikinci bir dil olarak öğrenen bireylerle iletişim kurmaktır (Pennycook, 1994; Clyne, 1994). (...) Yabancı kültür öğrenimi dil öğrenimine katk1 sunabilir. Tseng (2002: 13) bu durumu şu şekilde açıklar: "Dil öğrenimindeki başarı kültürel bilginin edinimine bağımlıdır. Bu nedenle dil öğrencileri hedef dilin kültürel alt yapısını öğrenerek hedef dildeki anlayış kapasitelerini artırabilirler."
\end{abstract}

- Yabancı dil öğrenimi dilbilgisi kurallarının kazanılmasının ötesine geçmelidir. Yabancı dil öğrencileri hedef dili uygun bağlamda kullanmaya gereksinim duyar (Neuner, 1997). Dili kültür olmaksızın öğretmek imkânsızdır. Çünkü dil kullanımı için gerekli bağlamı kültür sağlar (Stern, 1992: 205). Yabancı dilde kurulan bazı diyalog örnekleri göstermiştir ki doğru dilbilgisi yapılarının kullanıldığı durumlarda dahi kültürel öğeler hesaba katılmazsa yanlış anlaşılmalar ortaya çıkabilir (Willems, 1996; Tanaka, 1997).

- Yabancı dil öğretiminde dil kültür ilişkisi önemlidir. Çünkü kültür yabancı dil öğrencilerinin yetkin dil kullanıcıları olmasına yardım eder (Nault, 2006). Alptekin'in de (2002: 58) vurguladığ1 üzere yabancı dil öğretimi bireyin hedef kültürü ve o dili konuşanların dünya görüşünü ve kültürel çerçevesini, bakış açısını kazandığı bir tür kültürlenme sürecidir. Yabancı dil öğrenen bireyler yeni bir dünyayı tecrübe ederler.

\section{Kültürlerarası İletişim ve Kültürlerarası İletişimsel Yeti}

'Kültürlerarası iletişim' temel olarak farklı kültürlerden bireyler arasındaki iletişimdir. Samovar, Porter ve McDaniel (2010: 12) kültürlerarası iletişimi "kültürel algıları ve sembol sistemleri farklı insanlar arasındaki iletişim eylemleri" olarak ifade eder. Yabancı dil öğrenmenin amacı da temelde farklı kültürden bir bireyle iletişim kurmaktır. Çalışmamızın temel savı kültürel öğeleri dikkate almadan gerçekleştirilmeye çalışılan bir öğrenmenin eksik kalacağıdır. Benzer bir ifadeyle denilebilir ki dil her ne kadar soyut simgeler bütünü olarak algılansa da aslında bu simgeler bütünü içinde geliştiği kültürün bağlamından kopuk değildir. Kültürlerarası iletişimin 
doğrudan ilgili olduğu bir diğer kavram da 'kültürlerarası iletişimsel yetidir.' Gardner (1963: 243) kültürlerarası iletişimsel yetiyi "farklı kültürden bireylerle etkili ve uygun bir şekilde iletişim kurmak için gerekli bilgi, motivasyon ve tüm beceriler toplamı" olarak tanımlar. Bennet'e göre (2009: 122) "Kültürlerarası iletişim çeşitli kültürel bağlamlarda uygun ve etkili iletişim kurmamıza yardımcı olan çeşitli bilişsel, davranışsal ve kişisel özelliklerdir." Byram (2008: 27) ise kültürlerarası iletişimsel yetinin farklı kültürden biriyle iletişim kurma becerisi olduğunu vurgular. Diğer taraftan Fantini (1991:116) yukarıdaki tanımlara ilaveten jest, mimik, tonlama, beden duruşu gibi etmenlerin de kültürlerarası iletişimsel yetinin parçası olduğunu söyler. Yabancı dil öğretiminde kültürlerarası iletişimsel yetinin gelişim süreci incelendiğinde Chomsky (1957) tarafindan ortaya atılan ve bireyin herhangi bir dilde sonsuz bir üretimsel potansiyele sahip olduğunu savunan dilsel yetinin dil öğrenimi açısından ideal bir model olarak belirtildiği görülür. Hymes (1972) dilsel yetinin sosyokültürel öğeleri kapsamadığ için eksik bir model olduğu ifade etmiş; bir dilin içinde konuşulduğu bağlamı da hesaba katan iletişimsel yeti kavramını tanımlamıştır. Canale ve Swain (1980) ise iletişimsel yaklaşımın öğelerini "dilsel yeti, söylem yetisi, stratejik yeti ve sosyolinguistik yeti", olarak belirtmiştir. Bu alanda çalışma yapan diğer bir araştırmacı olan Van Ek de (1986) "sosyokültürel ve sosyal yetileri" ilave ederek iletişimsel yaklaşımın kapsamını genişletmiştir. Bununla birlikte iletişimsel yaklaşımın sadece işlevsel hedeflere odaklanması bazı yabancı dil öğretmenlerini memnun etmemiş, buna bağlı şekilde geleneksel iletişim yeteneklerinin kaynak ve hedef dillerin kültürel içeriklerini dikkate alan, insan odaklı şekilde geliştirilmesini amaçlayan arayışlar ortaya çıkmıştır (Kramsch, 1995: 83). Sonuç olarak; yukarıda tanımı yapılan kültürlerarası iletişimsel yetiyi de içine alacak şekilde genişleyen bu yaklaşım Byram (1997: 51) tarafindan şu şekilde açıklanır:

Kültürlerarası iletişimsel yeti dilsel ve sosyolinguistik yeteneklerin dişında çeşitli tutum, bilgi ve yetenekleri de gerektirir. Bu tutumlar hem merakı hem açık olmayı hem de kendi ve diğer kültürleri ön yargısız bir bakış açısıyla değerlendirmeyi içerir. Gerekli olan bilgi ise toplumsal gruplar ve bu grupların ürünlerini, geleneklerini kapsadığı gibi aynı zamanda muhatapların toplumsal ve bireysel etkileşimlerini de kapsar. Gerekli olan yetenekler ise kültürel farkındalığın/siyasi eğitimin dışında yorumlama, ilişkilendirme, keşfetme ve etkileşim becerilerini içerir.

Özetle; kültürlerarası iletişimsel yeti kültürlerarası iletişimin en temel parçasıdır ve bireyin farklı kültürler arasında iletişim kurabilmesiyle ilgili tüm becerilerin toplamıdır. Bu becerinin eksikliği başta önyargı olmak üzere kültür şoku, karşıdaki bireyi tek tipleştirme gibi birçok sorunun kaynağını oluşturabilir.

\section{Kültürlerarası İletişimsel Yetiyle İlgili Modellere Genel Bir Bakış}

$\mathrm{Bu}$ bölümde kültürlerarası iletişimsel yeti hakkında geliştirilen bazı temel yaklaşımlarla ilgili genel bir çerçeve çizilecektir. Bennet'in (1993) 'Kültürlerarası Gelişimsel Duyarlılık Modeli' bireyin etnik merkezcilikten başlayarak sürecin sonunda etnik göreceliğe ulaşacağını belirtir. $\mathrm{Bu}$ süreçte birey ilk önce karşı kültürle karşılaşır, bir sonraki adımda birey kendi kültürü ve karş1 kültür arasında içsel bir çatışma yaşar. En sonunda birey iki kültür arasında bir denge kurar ve diğer kültürün kendi kültüründen ne daha iyi ne de daha kötü olduğuna, sadece farklı olduğuna karar verir. Gudykunst'un (1993) modelinin temelinde bireyin öncelikle öz farkındalığa sahip olmasının gerekliliği vurgulanır. Böylece birey belirsizlik ve kaygıyı azaltarak kültürlerle etkileşime girebilir. Bu alandaki en etkili modellerden biri Byram (1997) tarafindan geliştirilmiştir. $\mathrm{Bu}$ modele göre kültürlerarası iletişimde başarılı olmak için çeşitli bilgi tutum ve yetenekler gereklidir. Deardorff (2006) ise kültürlerarası iletişimsel yeti modelinde bireyin bilgi, tutumlar gibi içsel etmenlerin yanında dışsal etmenleri de dikkate alarak hedef kültürle olan bağını geliştirebileceğini ifade eder. Kültürlerarası iletişimsel yeti hakkında yukarıda özetlenen 
modellerin dışında bir dizi farklı yaklaşımdan bahsetmek mümkündür. Gönül'ün (2007: 36) aktardığ tablo genel olarak bu alanda geliştirilen modelleri ve bu modellerin öğelerini içerir:

Tablo 1. Kültürlerarası İletişimsel Yeti Modelleri (Gönül, 2007:36)

\begin{tabular}{|c|c|c|c|c|}
\hline $\begin{array}{l}\text { Kültürlerarası } \\
\text { Davranışsal } \\
\text { Değerlendirme } \\
\text { Ölçeği } \\
\text { (Intercultural } \\
\text { Behavioral } \\
\text { Assessment } \\
\text { Indices) } \\
\text { (IBAI) } \\
\text { byRuben (1976) }\end{array}$ & $\begin{array}{l}\text { Kültürlerarası Yeti için } \\
\text { Davranış } \\
\text { Değerlendirme } \\
\text { Ölçeği } \\
\text { (Behavioral } \\
\text { AssessmentScale } \\
\text { For Intercultural } \\
\text { Communication } \\
\text { (BASICs of } \\
\text { Intercultural } \\
\text { Competence)by } \\
\text { Koester\&Olebe (1987) }\end{array}$ & $\begin{array}{l}\text { Kültürlerarası } \\
\text { Yeterlilik } \\
\text { Değerlendirmesi } \\
\text { (The Intercultural } \\
\text { Competence } \\
\text { Assessment) (INCA) } \\
\text { Project (2004) }\end{array}$ & $\begin{array}{l}\text { Amaçlar } \\
\text { Öneriler ve } \\
\text { Değerlendirme } \\
\text { (Your } \\
\text { Objectives } \\
\text { Guidelines } \\
\text { and } \\
\text { Assessment) } \\
\text { (YOGA) by } \\
\text { Form Fantini (2000) }\end{array}$ & $\begin{array}{l}\text { Kültürleraras1 } \\
\text { Yeterlilik } \\
\text { (Intercultural } \\
\text { Competence) } \\
\text { byByram (1997) }\end{array}$ \\
\hline $\begin{array}{l}\text { 1. Saygi (Respect) } \\
\text { 2.Karşlılılı } \\
\text { etkileşim } \\
\text { (Interaction } \\
\text { posture) } \\
\text { 3. Uyum Bilgisi } \\
\text { (Orientation } \\
\text { Knowledge) } \\
\text { 4.Empati } \\
\text { (Empathy) } \\
\text { 5.Davranışlar } \\
\text { (Role Behaviour) } \\
\text { - Görevsel Roller } \\
\text { (Task Roles) } \\
\text { - Ilisskisel Roller } \\
\text { (Relational Roles) } \\
\text { - Bireysel Roller } \\
\text { (Individualistic } \\
\text { Roles) } \\
\text { 6.Etkileşim } \\
\text { Yönetimi } \\
\text { (Interaction } \\
\text { Management) } \\
\text { 7.Belirsizliğe } \\
\text { Tahammül } \\
\text { (Ambiguity } \\
\text { Tolerance) }\end{array}$ & $\begin{array}{l}\text { 1.Saygı (Gösterimi) } \\
\text { (Display of) Respect) } \\
\text { 2.Karşllklı Etkileşim } \\
\text { (Interaction Posture) } \\
\text { 3. Bilgi Uyumu } \\
\text { (Orientation to } \\
\text { Knowledge) } \\
\text { 4.Empati (Empathy) } \\
\text { 5.Davranışlar (Role } \\
\text { Behaviour) } \\
\text { - Görevsel } \\
\text { Roller (Task } \\
\text { Roles) } \\
\text { - İlişkiselRoller } \\
\text { (RelationalRoles) } \\
\text { 6.Etkileşim Yönetimi } \\
\text { (Interaction } \\
\text { Management) } \\
\text { 7.Belirsizliğe } \\
\text { Tolerans(Ambiguity } \\
\text { Tolerance) }\end{array}$ & $\begin{array}{l}\text { 1. Açıklık (Openness) } \\
\text { - Başkalarına saygı } \\
\text { (Respect for } \\
\text { Otherness) } \\
\text { - Belirsizliğe } \\
\text { Tolerans } \\
\text { (Tolerance } \\
\text { Ambiguity) } \\
\text { 2. Bilgi (Knowledge) } \\
\text { - Bilgi keşfi } \\
\text { (Knowledge } \\
\text { Discovery) } \\
\text { - Empati (Empahty) } \\
\text { 3.Uyum } \\
\text { (Adaptability) } \\
\text { - Davranısssal } \\
\text { esneklik } \\
\text { (Behavioral } \\
\text { flexibility) } \\
\text { - İletişimsel } \\
\text { Farkındalık } \\
\text { (Communicative } \\
\text { Awareness) }\end{array}$ & $\begin{array}{l}\text { 1. Farkındalık } \\
\text { (Awareness) } \\
\text { 2.Tavir/Tutum } \\
\text { (Attitude) } \\
\text { 3. Yetenekler } \\
\text { (Skills) } \\
\text { 4. Bilgi } \\
\text { (Knowledge) } \\
\text { 5. Dil } \\
\text { Yeterliliği } \\
\text { (Language } \\
\text { Proficiency) }\end{array}$ & $\begin{array}{l}\text { 1.Davranışlar } \\
\text { (Attitudes) } \\
\text { (savoiretre) } \\
\text { 2. Bilgi } \\
\text { (Knowledge) } \\
\text { (savoirs) } \\
\text { 3.İlişki kurma ve } \\
\text { yorumlama } \\
\text { becerisi (Skills of } \\
\text { interpreting and } \\
\text { relating) (savoir } \\
\text { comprendre) } \\
\text { 4. Karş1liklı } \\
\text { etkileşim ve } \\
\text { keşfetme becerisi } \\
\text { (Skills of } \\
\text { Discovery and } \\
\text { interaction) } \\
\text { (savoir } \\
\text { apprende/faire) } \\
\text { 5.Eleştirel } \\
\text { kültürel } \\
\text { uyanılklikisiyasi } \\
\text { eğitim (Critical } \\
\text { cultural } \\
\text { awareness) } \\
\text { (savoirs' } \\
\text { Engager) }\end{array}$ \\
\hline
\end{tabular}

Daha önce de belirtildiği üzere yabancı dil öğrenmenin amacı farklı kültürden bir bireyle iletişim kurmaktır. Dolayısıyla doğru bir kültürlerarası iletişimin sağlanması yabancı dil öğretimi için de elzemdir. $\mathrm{Bu}$ nedenledir ki kültürlerarası iletişimin önündeki engeller yabancı dil öğretiminin önündeki engellerle aynı çerçevede değerlendirilebilir. $\mathrm{Bu}$ kısımda kültürlerarası iletişimin önündeki engeller açıklanacaktır.

\section{Kültürlerarası İletişimin Önündeki Engeller}

Kültürlerarası iletişimin önündeki engeller Jandt'tan (2018: 103-180) aşağıdaki gibi özetlenmiştir: 
Kaygı: Birey kendisinden ne beklendiğini anlayamadığ 1 durumlarda kaçınılmaz olarak duygulara odaklanır ve iletişim sürecinden uzaklaşır ve böylece kaygı doğar. Örneğin; bir birey yabancı bir ülkeye gittiğinde o ülkenin dilini belirli bir düzeyde konuşsa dahi iletişim sırasında kaygı yaşaması olasıdır. Çünkü birey içinde kendini güvende hissettiği kültürel kodlardan, benzer bir ifadeyle onun için toplumsal yaşamı anlamlandıran sembollerden uzaklaşmıştır. Jandt(2018: 112) kültürlerarası iletişim kaygısı hakkında Sugawara (1993) tarafından yapılan çalışmayı şu şekilde aktarır:

Çalışmada ABD'de bulunan bir şirketin yüz altmış sekiz Japon, yüz otuz beş Amerikalı çalışanı ile görüşme yapılmıştır. Çalışmanın sonuçlarına göre Amerikalı çalışanların sadece $\% 8$ 'i Japon çalışanların İngilizcesinden rahatsız olduklarını belirtmiştir. Japon çalışanların ise \%19'u İngilizcelerinin zayıf veya çok zayıf olduğunu, \%20'lik bir kesim Amerikalı iş arkadaşlarıyla konuştuklarında gergin hissettiklerini, \%30'luk bir kesim de Amerikalı iş arkadaşlarının Japon çalışanların İngilizce aksanlarından rahatsız olduğunu düşündüklerini ifade etmişlerdir. Japon çalışanların neredeyse \%60'1 Amerikalı iş arkadaşlarıyla iletişim kurarken dilin bir sorun oluşturduğuna inandıklarını vurgulamıştır. Bazı Japon çalışanlar için düzgün İngilizce konuşamama kaygısı gerek iş hayatında gerekse dışarıda Amerikalı iş arkadaşlarıyla iletişimden kaçınmalarına neden olmaktadir.

Neuliep ve McCroskey (1997: 145) son yirmi beş yılda iletişim kaygısı alanında yapılan çalışmaların yoğunlaştığını ve çeşitli araştırmacılara göre (Levine ve McCroskey, 1990; Lustig ve Andersen, 1991; Payne ve Richmond, 1984) bu durumun iletişimin önündeki temel engel olarak görüldüğünü vurgular. Çiloğlan da (2019) benzer şekilde iletişim ve kaygı arasındaki ilişkiye atıfta bulunur. Yenilik, bilinmezlik, farklılık ve belirsizlik gibi durumlar özellikle farklı kültürden gelen bireyler arasında kaygıya neden olabilir. Dolayısıyla kültürlerarası iletişim ve yabancı dil öğretimi alanında da kaygının temel bir engel olduğu söylenebilir. Bu nedenle kaygının ölçülmesi iletişim sürecinin niteliğini belirlemek için gerekli ve önemlidir.

Her Şeyin Benzer olduğunu Farz Etmek: Kültürlerarası iletişimin önündeki bir diğer engel de bireyin kültürel farkları, gelenekleri, normları hesaba katmaksızın her şeyin her yerde aynı olduğunu farz etmesidir. Bir başka ifadeyle; bireyin kendi kültürünü merkeze alarak başka kültürlerin herhangi bir konuda farklı bir bakış açısı geliştirebileceği ihtimalini görmezden gelmesidir. Ön kabullerin iletişim sürecini sekteye uğratması olasıdır. Jandt (2018: 113) bu durumu ABD Manhattan'da Danimarkalı bir kadının kafeteryada yemek yerken on dört aylık bebeğini kafeteryanın önünde gözetimsiz olarak bebek arabasında bırakması örneği ile açılar. Çevredeki insanlar bebeği bu şekilde görünce polisi aramıştır ve anne, bebeğin hayatını tehlikeye atmaktan iki gün hapiste kalmıştır. Bebek de bu süre boyunca koruyucu aileye verilmiştir. Aslında Danimarka'da anne babalar restoranlarda yemek yerken bebeklerin dışarıda bebek arabasında kalması yaygın bir gelenektir. Fakat Danimarkalı çiftin hatası Amerika'da da durumun bu şekilde olduğunu farz etmeleriydi. Sonuçta Danimarka büyükelçisinin durumu fotoğrafla açılamasıyla sorun çözülmüştür. Özetle; gelenek ve görenekler kültürden kültüre farklılık gösterebilir, bu durumu göz önünde bulundurmamak kültürlerarası iletişimi olumsuz etkileyebilir.

Etnik Merkezcilik: Etnik merkezcilik bireyin kendi kültürüne odaklanarak başka bir kültürün özelliklerine ön yargı ile bakması ya da o kültürü sadece farklı olduğu için eleştirmesidir. Etnik merkezci birey kendi kültürünün daha üstün olduğu kabulü ile hareket eder ve diğer tüm kültürlerin değersiz olduğuna inanır. Jandt (2018: 116) sıcak iklimli birçok ülkede günün en sıcak saatlerinin siesta olarak bilinen bir tür öğle uykusu ile geçirilmesinin diğer ülkelerde tembellik olarak algılanmasını etnik merkezciliğin örneği olarak gösterir. Aslına bakılırsa siesta günün geri kalanını daha verimli geçirmek için oldukça faydalıdır. Bununla birlikte birey kendi kültürünü 
merkeze alarak bu duruma olumsuz bir pencereden bakabilir ve sonuç olarak kültürlerarası iletişimin önüne bir engel çıkmış olur.

Tek Tipleştirme ve Ön Yargı: Tek tipleştirme bireyler hakkında gözlemlenen veya bir grupta var olduğuna inanılan nitelikleri, olumlu ya da olumsuz yargıları kapsar. Örneğin; tüm Almanlar çalışkandır, tüm Amerikalılar dost canlısıdır, tüm İngilizler soğuktur gibi ifadeler aşırı genellemeden kaynaklanır ve kültürlerarası iletişimin önündeki keskin bir engeldir. Aslında tek tipleştirme diğer bireyler hakkında zihnimizi zorlamadan fikir yürütmemize yardımcı olduğu için çoğunlukla sorgulanmadan kabul görür. Diğer taraftan ön yargı ise 1rk, din, dil, cinsel tercih gibi nedenlere bağlı olarak ortaya çıkan mantıksız şüphe ya da nefret duygusudur. Ön yargı ve tek tipleştirme kültürlerarası iletişim açısından ciddi birer tehdit oluşturur.

Barna (1998: 173-174) kültürlerarası iletişimi engelleyen etmenler konusunda Jandt'a (2018) ek olarak aşağıdaki faktörlerden bahseder:

Yanlış Anlama ve Reddetme: İletişim kurulan bireyin insan olması tek başına iletişimin başarılı olması için yeterli bir koşul değildir. Daha açık bir ifadeyle, iletişimin her iki tarafı da aynı temel ihtiyaçlara sahiptir; ama bu ihtiyaçların ifade ediliş ve karşılanış tarzı kültüre özgüdür ve bu nedenle bir kültürden diğerine farklılık gösterebilir.

Bireylerin Sözlü/Sözsüz İletişim Diline Hâkimiyetleri: İletişim kuran bireylerin gerek sözlü gerek sözsüz iletişim diline, jestlere, mimiklere, aksana, tonlamaya, argo söyleyişlere hâkim olması iletişimin başarılı bir şekilde sürdürülmesi için gereklidir. Aksi bir durumda iletişim sürecinin sekteye uğraması çok muhtemeldir.

Sözsüz Mesajların Yanlış Yorumlanması: Jest, mimik, vücut duruşu gibi sözlü olmayan mesajların yanlış yorumlanması iletişimin başarısız olma ihtimalini yükseltir.

Sonuç olarak; yabancı dil öğretiminde yukarıdaki engellerin özellikle de kaygının göz önünde bulundurulması önemlidir. Bir Lingua Franca olarak İngilizce günümüzde farklı toplumlar için ortak iletişim dili niteliği taşır. Bununla birlikte her birey belirli bir kültürel geçmiş ile var olur. İster ana dili İngilizce olan bireylerle isterse de üçüncü bir grup ile iletişim kurmak için İngilizce öğrenilsin bu kültürel kodlar hesaba katılmalıdır. Böylece sağlıklı bir iletişim kurulabilir. Bu bağlamda çalışmamızda aşağıdaki soruların yanıtı aranmaktadır:

- Kaygı ile kültürlerarası iletişim arasındaki iliş̧ki yabancı dil öğretim sürecinde etkili midir?

- $\mathrm{Bu}$ tür bir ilişki varsa cinsiyet, yurt dışı tecrübesi gibi demografik değişkenlerin bu ilişki üzerinde ne tür bir etkisi vardır?

- Kültürlerarası iletişim kaygısının yabancı dil öğretimi üzerindeki muhtemel etkileri nasıl azaltılabilir?

\section{Yöntem}

Çalışma öncesi Kocaeli Üniversitesi Etik Kurulu'ndan 16/04/2020 tarih ve 2020/06 sayı ile gerekli izin alınmıştır. Çalışmamızda 'özel durum yöntemi’ kullanılmıştır. Ekiz (2013: 45) özel durum yönteminin temel özelliklerini şu şekilde aktarır:

“Özellikle sosyal bilimlerde (sosyoloji, antropoloji, tarih, psikoloji, eğitim), özel durum araştırması çeşitli konuları araştırmak için yoğun bir şekilde kullanılıp, çoğunlukla nitel araştırma yaklaşımı içerisinde görülmekte ve bu yaklaşımın en önemli özelliklerinden birisi olarak değerlendirilmektedir (Stake, 1995). En belirgin niteliği ise, güncel bir olgu, olay, durum, birey ve gruplar üzerine odaklanılıp, derinlemesine incelemeye çalışmasıdır (Bassey, 1999; Stake, 1995; Yin, 1994). 
Ekiz (2013) özel durum araştırmasının diğer yöntemlerden temel farkının eğitimin çeşitli konularında 'nasıl' ve 'niçin' soruları sorulduğunda tercih edilmesi olduğunu vurgular. Bu yöntemde araştırmacı özel bir durumu önyargılarından uzak durarak derinlemesine inceler ve survey (tarama) türü araçlar vasıtasıyla veri toplar. Bu bağlamda çalışmada özel durum yöntemine uygun şekilde veri toplama aracı olarak Likert Tipi ölçek kullanılmıştır. Genel olarak ölçekler bireylerin tutum ve davranış eğilimleri gibi soyut kavramların ölçülmesinde kullanılan araçlardır. Karasar'a göre (2003:140) ölçekler görüş ve tutumları ölçmeyi amaçlayan ölçekler olmak üzere iki kategoride incelenebilir. Çalışmada kullanılan Likert Tipi ölçek, bir tutum ölçeğidir. Bayat (2014:22-23), Likert Tipi Ölçeğin temel niteliklerini aşağıdaki gibi sıralamıştır:

- Likert ölçekleri bir "toplamalı sıralama" tekniğidir. Yani, sadece cevaplayıcının ölçekten elde ettiği "toplam puan/toplam ölçek puanı" anlamlıdır.

- Dolayısı ile sadece ve sadece bir tek özelliği ölçmek üzere geliştirilirler (ölçekleme tekniğinin tek boyutluluk özelliği).

- Bir Likert ölçeği ile birden fazla özellik aynı anda/aynı ölçekte ölçülemez.

- Likert ölçeklemesinde araștırlan özellikler "o özelliği somutlaştıran önermeler şeklinde tasarlanmalıdır". Likert ölçeklerinin yapısı soru şeklinde tasarıma uygun değildir.

- Likert ölçeklemesinde hangi tepki/cevap seçeneği/türü kullanılırsa kullanılsın puanlama birden (1) başlar. Puanlama sıfırdan (0) başlatılamaz.

- Ölçekte yer alan; "olumlu önermelere verilen en olumlu cevap/tepki" ve "olumsuz önermelere verilen en olumsuz cevap/tepki" beş (5) puan, "olumlu önermelere verilen en olumsuz cevap/tepki" ve "olumsuz önermelere verilen en olumlu cevap/tepki" bir (1) puan alacak şekilde tasarlanır ve puanlanır.

Çalışmada kullanılan ölçek Neuliep ve McCroskey (1997) tarafindan 'Intercultural Communication Apprehension Scale (Kültürlerarası İletişim Kaygısı Ölçeği)' ismiyle geliştirilmiş olup kaygının kültürlerarası iletişim üzerindeki etkisini ölçmek amacı taşımaktadır. Daha sonra Türkoğlu vd. (2018) bu ölçeği Türkçeye uyarlayıp, ölçeğe geçerlik ve güvenirlik testlerini uygulamıştır. Alınan izinler doğrultusunda bu ölçek Kocaeli İli merkezinde bulunan özel bir yabanc1 dil okulunda eğitim alan ve tamamı Kocaeli Üniversitesi öğrencisi olan yüz kırk (140) katılımcıya uygulanmıştır. Katılımcı sayısı belirlenirken ölçekteki madde sayısını 10 katı olmasına dikkat edilmiştir (Büyüköztürk, 2005).

\section{Katılımcıların Demografik Özellikleri}

Seçkisiz örneklem yöntemiyle seçilen katılımcıların tamamı Kocaeli Üniversitesi öğrencilerinden oluşmaktadır. 61 katılımcı erkek, 79 katılımcı kadındır. Katılımcılar, 19-23 arasındaki bireylerden oluşmaktadır. Katılımcıların 111'i daha önce yurt dışında bulunmuşken 29'u yurt dışına çıkmadıklarını ifade etmiştir. 116 katılımcı İngilizce dışında bir dil bilmeyen bireylerden, 24'ü ise İngilizce dışında ikinci bir yabancı dil bilen bireylerden oluşmaktadır.

\section{Uygulama}

Araştırmada kullanılan ölçek 14 maddeden oluşmaktadır. Ölçeğin aslında her bir madde "kesinlikle katılmıyorum" (1 puan) ile "kesinlikle katılıyorum" (5 puan) arasında değişen 5'li likert tipi şeklinde derecelendirilmiştir. Ölçek maddeleri 1-5 puan arasında puanlanmaktadır. Ölçek toplam puanı hesaplanırken; 
1. Adım: 2,4,6,8,11,13,14 nolu maddelerin puanları ters çevrilir. Bu dönüşüm şu şekildedir: 1 puan 5 puana, 2 puan 4 puana, 4 puan 2 puana, 5puan ise 1 puana dönüştürülürken 3 puan ise aynı kalır.

2. Adım: 14 maddenin puan değerleri toplanır.

Ölçekten en düşük 14, en yüksek 70 puan alınmaktadır. Katılımcı puanları şu şekilde değerlendirilir:

- 0-29 puan arası düşük kültürlerarası iletişim kaygısı,

- 30-49 puan arası orta düzeyde kültürlerarası iletişim kaygıs1,

- 50-70 puan arası yüksek kültürlerarası iletişim kaygısı (Türkoğlu, 2018; McCroskey, 1997).

\section{Analiz ve Bulgular}

Bir önceki bölümde verilen formül ile katılımcıların kültürlerarası iletişimsel kaygısı hesaplanmıştır. Elde edilen değerler SPSS Statistics 20 Programı ile analiz edilmiştir. Ortaya çıkan frekans değerleri aşă̆ıdaki gibidir:

Tablo 2, çalışmadaki analiz değişkenlerini göstermektedir.

Tablo 2. Analizin Değișkenlerini

\begin{tabular}{|l|r|r|r|r|r|}
\hline & Kaygı & Yurtdışı & İkinci dil & Cinsiyet & \multicolumn{2}{|c|}{ Yaş } \\
\hline Geçerli & 140 & 140 & 140 & 140 & 140 \\
Kayıp & 0 & 0 & 0 & 0 & 0 \\
\hline
\end{tabular}

Tablo 2'ye göre çalışmanın analiz değişkenleri kaygı, yurt dışı tecrübesi, ikinci yabancı dil, cinsiyet ve yaşı kapsamaktadır.

Tablo 3, katılımcıların kaygı düzeylerini göstermektedir.

Tablo 3. Katılımcıların Kültürlerarası İletișim Kaygı Düzeyleri

\begin{tabular}{|rl|r|r|r|r|}
\hline & Siklık & \multicolumn{1}{|c|}{ Yüzde } & Geçerli Yüzde & \multicolumn{2}{|c|}{$\begin{array}{c}\text { Toplam } \\
\text { Yüzde }\end{array}$} \\
\hline \multirow{6}{*}{ Geçerli } & Düşük & 11 & 7,9 & 7,9 & 7,9 \\
& Orta & 74 & 52,9 & 52,9 & 60,7 \\
& Yüksek & 55 & 39,3 & 39,3 & 100,0 \\
& Toplam & 140 & 100,0 & 100,0 & \\
\hline
\end{tabular}

Tablo 3'e göre katılımcıların \%7,9'u düşük, \%52,9'u orta ve \%39,3'ü yüksek kültürlerarası iletişim kaygısına sahiptir. Katılımcıların büyük çoğunluğunda orta ve ileri düzey kültürlerarası iletişimsel kaygı görülmektedir.

Tablo 4, katılımcıların yurt dışı tecrübesi olup olmadığını incelemektedir. 
Tablo 4. Katılımcıların Yurt Dışı Tecrübesi

\begin{tabular}{|c|c|c|c|c|c|}
\hline & & Siklik & Yüzde & Geçerli Yüzde & $\begin{array}{l}\text { Toplam } \\
\text { Yüzde }\end{array}$ \\
\hline & Var & 29 & 20,7 & 20,7 & 20,7 \\
\hline Geçerli & Yok & 111 & 79,3 & 79,3 & 100,0 \\
\hline & Toplam & 140 & 100,0 & 100,0 & \\
\hline
\end{tabular}

Tablo 4'e göre katılımcıların \%20,7'si yurt dışı tecrübesine sahipken, \%79,3'ü daha önce yurt dışında bulunmamıştır.

Tablo 5, Katılımcıların İngilizce dışında bir başka yabancı dil bilip bilmediğini incelemektedir.

Tablo 5. Katılımcıların İngilizce Dışında Yabancı Dil Bilgisi

\begin{tabular}{|r|r|r|r|r|r|}
\hline & Siklık & & \multicolumn{1}{|c|}{ Yüzde } & \multicolumn{1}{|l|}{ Geçerli Yüzde } & \multicolumn{2}{|c|}{$\begin{array}{c}\text { Toplam } \\
\text { Yüzde }\end{array}$} \\
\hline \multirow{6}{*}{ Geçerli } & Var & 24 & 17,1 & 17,1 & 17,1 \\
& Yok & 116 & 82,9 & 82,9 & 100,0 \\
& Toplam & 140 & 100,0 & 100,0 & \\
\hline
\end{tabular}

Tablo 5'e göre kat1lımcıların \%17,1'i ikinci bir yabanc1 dil bilirken, \%82,9'u sadece İngilizce bilmektedir.

Tablo 6, katılımciların cinsiyetlerini incelemektedir.

Tablo 6. Katılımcıların Cinsiyetleri

\begin{tabular}{|c|c|c|c|c|c|}
\hline & & Siklık & Yüzde & Geçerli Yüzde & $\begin{array}{l}\text { Toplam } \\
\text { Yüzde }\end{array}$ \\
\hline \multirow{3}{*}{ Geçerli } & Erkek & 61 & 43,6 & 43,6 & 43,6 \\
\hline & Kadın & 79 & 56,4 & 56,4 & 100,0 \\
\hline & Toplam & 140 & 100,0 & 100,0 & \\
\hline
\end{tabular}

Tablo 6'ya göre katılımcıların \% 43,6's1 erkeklerden, \%56,4'ü kadınlardan oluşmaktadır

Ölçekteki her bir değişkenin oransal değeri incelendikten sonra çapraz karşılaştırma ile değişkenlerin birbiri ile ilişkisi olup olmadığına bakılmıştır:

Tablo 7, İngilizce dışında yabancı dil bilgisi ile kültürlerarası iletişim kaygısı arasındaki ilişkiyi analiz etmektedir. 
Tablo 7. İngilizce Dışında Yabancı Dil Bilgisi ile

Kültürlerarası İletişim Kaygısı İlişkisi

\begin{tabular}{|c|c|c|c|c|}
\hline & \multicolumn{2}{|c|}{ İkinci dil } & \multirow[t]{2}{*}{ Total } \\
\hline & & Var & Yok & \\
\hline \multirow{3}{*}{ Kayg1 } & Düşük & 2 & 9 & 11 \\
\hline & Orta & s & 65 & 74 \\
\hline & Yüksek & 13 & 42 & 55 \\
\hline Toplan & & 2 & 116 & 140 \\
\hline
\end{tabular}

Tablo 7incelendiğinde düşük kaygılı 11 bireyin 2'sinin $(\% 18,18)$ İngilizce dışında bir dil bildiği, 9'nun $(\% 81,81)$ ise ikinci bir yabancı dil bilmediği görülür. Orta düzey kaygı gösteren 74 bireyin 65'i $(\% 87,83)$ İngilizce dışında ikinci bir yabancı dil bilmezken, 9'u $(\% 12,16)$ bilmektedir. Yüksek kaygı düzeyine sahip 55 öğrenciden 42'si $(\% 76,36)$ İngilizce dışında ikinci bir yabancı dil bilgisine sahipken, 13’ü $(\% 23,63)$ sahip değildir.

Tablo 8, cinsiyet ile kültürlerarası iletişim kaygısı ilişkisini göstermektedir.

Tablo 8. Cinsiyet ile Kültürlerarası İletişim Kaygısı İlișkisi

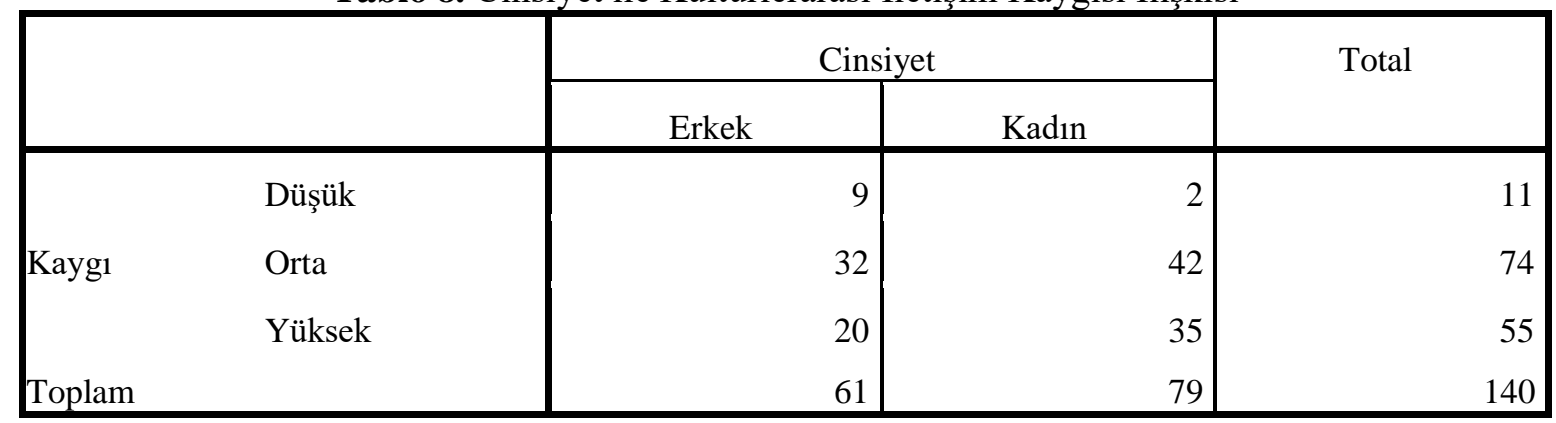

Tablo 8'deki verilere göre düşük kaygı gösteren 11 bireyin 9'unun (\%81,81) erkek, 2'sinin $(\% 18,18)$ kadın; orta düzey kaygı gösteren bireylerin 74 bireyin 32 'sinin $(\% 43,24)$ erkek, 42 'sinin $(\% 56,65)$ kadın; yüksek düzey kayg1 gösteren 55 bireyin 20'sinin $(\% 36,36)$ erkek, 35'inin $(\% 63,63)$ kadın olduğu görülmektedir.

Tablo 9, yurt dışı tecrübesi ve kültürlerarası iletişim kaygısı ilişkisini incelemektedir.

Tablo 9. Yurt Dışı Tecrübesi ile Kültürlerarası İletişim Kaygısı İlişkisi

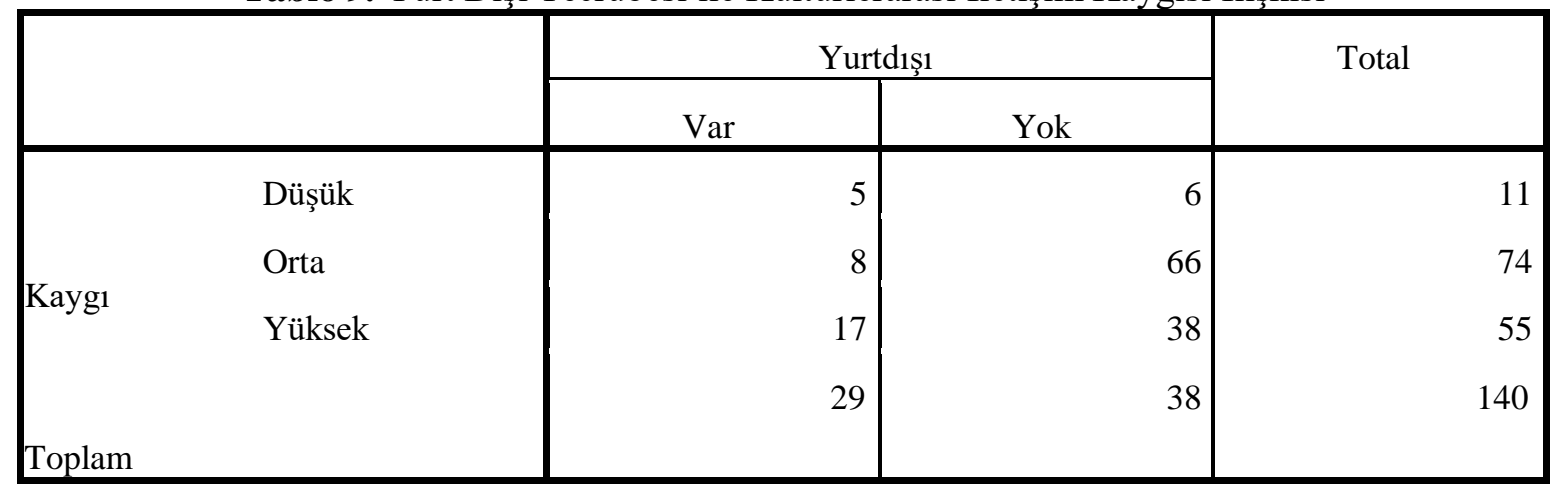

Turkish Studies - Education, 15(4) 
Tablo 9'a göre düşük kaygı düzeyi sergileyen 11 bireyin 5'i $(\% 45,45)$ daha önce yurt dişında bulunmuşken, 6'sı $(\% 54,54)$ bulunmamıştır. Orta düzey kaygıya sahip 74 bireyin 66'sının $(\% 89,18)$ yurt dışı tecrübesi vardır; fakat 8 'inin $(\% 10,81)$ yoktur. Yüksek kaygı gösteren 55 öğrencinin 38'inin $(\% 69,09)$ yurt dışı tecrübesi yoktur. Bu bireylerin 17'si $(\% 22,97)$ ise daha önce yurt dışına çıkmıştır.

\section{Tartışma ve Sonuç}

Kaygı insan hayatının her evresi üzerinde ciddi bir etkiye sahiptir. Farklı kültürlerden gelen bireylerin iletişim kurması da kaygının etkisinden bağımsız değildir. Bu bağlamda yabancı dil öğretimi sürecinde de kültürlerarası iletişim kaygısı göz önünde bulundurulmalıdır. Bu çalışmada kültürlerarası iletişim kaygısı ile yabancı dil öğretimi arasındaki ilişki incelenmiştir. Uygulama kısmında Neuliep ve McCroskey (1997) tarafından geliştirilen ve Türkoğlu (2018) tarafından Türkçeye uyarlanan 'Kültürlerarası İletişim Kaygısı Ölçeği' kullanılmıştır. Çalışmanın katılımcıları Kocaeli'de özel bir dil okulunda İngilizce öğrenen Kocaeli Üniversitesi öğrencileri arasından seçkisiz örneklem yöntemiyle seçilmiştir. Katılımcılar yabancı dil dersleri esnasında hem anadili İngilizce olan öğretmenlerle iletişim kurmakta hem de hedef dilin kültürüne ait çeşitli deneyimleri yaşamaktadırlar. $\mathrm{Bu}$ iletişim etkinlikleri sürecinde yaşanması muhtemel kültürlerarası iletişim kaygısının katılımcıların yabancı dil öğrenmeleri üzerindeki etkisini ölçmeyi amaçlayan analiz sonucunda katılımcıların \%7,9'unda düşük kaygı görülmüştür. Diğer katılımcıların ise \%52,9’u orta ve \%39,3'ü yüksek düzey kültürlerarası iletişim kaygısına sahiptirler. Rafek vd.'nin (2013: 92) aktardığı üzere kültürlerarası iletişim kaygısı ne kadar yüksekse öğrencilerin iletişim süreci o kadar olumsuz etkilenir. Diğer taraftan Hamamc1 (2015: 376) bu alanda yapılan çalışma sonuçlarını şu şekilde aktarır:

1960'lı yılların ortalarından beri araştırmacılar kaygının yabancı ya da ikinci dil öğrenimini engellediğini düşünmüşlerdir (Ewald, 2007). Birçok araştırmanın bulguları biraz gerginliğin öğrencileri güdüleyebileceğini ve hatta onların dil öğrenmelerini hızlandırabileceğini belirtirken (örneğin, Spielmann \& Radnofsky, 2001), diğer araştırmalar (örneğin, Gregersen, 2003; Gregersen \& Horwitz, 2002; Horwitz, 1995, 2001; Sparks \& Ganschow, 2007; Spielmann \& Radnofsky, 2001; Young, 1999) kaygının yabancı dil öğrenimindeki olumsuz etkisini vurgulamışlardır. Kaygının öğrencilerin yabancı dil öğrenimine olumsuz etkisi olduğunu vurgulayan çalışmalar, öğrencilerin yaşadıkları yabancı dil kaygısını azaltan Doğal Yaklaşım (Krashen \& Terrrell, 1983), Topluluk Dil Öğrenimi (Curran, 1972) ve Telkin (Lozanov, 1978) yabancı dil öğretim yöntemlerinin ortaya çıkmasına da katkıda bulunmuşlardır.

Öğrencilerin kültürlerarası iletişim kaygısını azaltmak için öncelikle hedef ve kaynak kültürler arasındaki benzerlikler vurgulanmalı; farklar ikinci plana atılmalıdır. Dahası hedef dilin sadece bir iletişim aracı olduğu vurgulanmalı; bu durumun kültürlerarası bir üstünlük nedeni olmadığı ifade edilmelidir. Her iki dilin ve her iki kültürün değerli olduğu belirtilmelidir. Günümüzde küreselleşme nedeniyle Anglosakson kültürünün giderek yaygınlaşması İngilizce öğretimi açısından bir avantaj oluşturur. Buna karşılık kaynak kültürün de aynı derece değerli ve kendine özgü olduğu belirtilmelidir ki bu durum kültürlerarası iletişim kaygısını azaltmakta faydalı bir araç olabilir.

Çalışmamızda kültürlerarası iletişim kaygısı ile bazı tanımlayıcı değişkenler arasında çapraz karşılaştırma yapılmıştır. İngilizce dışında ikinci bir yabancı dil bilmenin kültürlerarası iletişim kaygısı üzerinde herhangi bir etkisi olup olmadığını belirlemeyi amaçlayan karşılaştırma sonuçları ise şu şekildedir:

- Düşük kültürlerarası iletişim kaygılı bireylerin \%18,18'i İngilizce dışında bir dil bilirken, $\% 81,81$ 'i ikinci bir yabanc1 dil bilmemektedir. 
- Orta düzey kültürlerarası iletişim kaygısı gösteren katılımcıların \%87,83'ü İngilizce dışında ikinci bir yabancı dil bilmediklerini ifade etmiştir. Diğer taraftan aynı grubun \%12,16'sı ikinci bir yabancı dil bilmektedir.

- Yüksek kültürlerarası iletişim kaygısı gösteren öğrencilerin \%76,36'sı İngilizce dışında ikinci bir yabancı dil bilgisine sahipken,\%23,63'ü sahip değildir.

$\mathrm{Bu}$ veriler ışığında İngilizce dışında ikinci bir yabancı dil bilgisine sahip olmak ile kültürlerarası iletişim kaygısı arasında anlamlı bir ilişki olmadığı söylenebilir. Öte yandan ikinci bir yabancı dil bilmenin öğrencilerin yabancı dil tecrübesini arttıracağını belirten Hamamcı (2015: 377) bu konuda alanda yapılan çalışmaları şu şekilde aktarmıştır:

Öğrenciler dil öğrenimi tecrübesi kazandıkça ve yüksek seviyede dil yetisine sahip olduklarında yabancı dil kaygıları azalmaya başlamaktadır. Örneğin, Gardner, Tremblay ve Masgoret'in (1997) yaptıkları araştırma, Gardner, Smythe ve Clement'in (1979) Fransızca konuşmaya yönelik kaygılarının sadece 5 ya da 6 haftalık yoğun bir kurstan sonra dil yeterliğinin öz güven üzerindeki olumlu etkisi sebebiyle azaldığını göstermiştir. Diğer araştırmacılar bir dönemlik yoğun dil öğrenimi sonrasında öğrencilerin kaygı seviyelerinde benzer azalmalar olduğunu gözlemlemişlerdir (Baker \& MacIntyre, 2000; Tanaka \& Ellis, 2003).

Cinsiyet ile kültürlerarası iletişim kaygısı arasındaki ilişkiyi inceleyen karşılaştırma sonuçları aşağıdaki gibidir: kadındır.

Düşük kültürlerarası iletişim kaygısı gösteren öğrencilerin \%81,81’i erkek, \%18,18’i

- Orta düzey kültürlerarası iletişim kaygısına sahip bireylerin \%43,24’ü erkeklerden, $\% 56,65$ 'i kadınlardan oluşmaktadır.

- Yüksek kültürlerarası iletişim kaygısı sergileyen katılımcıların \%36,36'sı erkek, $\% 63,63$ 'ü kadındır.

$\mathrm{Bu}$ veriler 1şı̆̆ında kadın katılımcıların orta ve yüksek kültürlerarası iletişim kaygı düzeylerinin erkeklerden fazla olduğu ifade edilebilir. Kaygı düzeyi arttıkça kadın katılımcıların oranının arttığ 1 görülmektedir. Bu durumun nedeni ayrı bir çalışma konusu olarak incelenebilir. Diğer taraftan Hamamcı'nın (2015:377) Aydın ve Takkaç'tan (2007) aktardığı çalışmanın sonucuna göre cinsiyet ve yabancı dil öğrenim kaygısı arasında anlamlı bir ilişki bulunamamıştır.

Katılımcıların yurt dışı tecrübesi ile kültürlerarası iletişim kaygısı arasındaki ilişki incelendiğinde ortaya çıkan sonuçlar aşağıdaki gibidir:

- Düşük kültürlerarası iletişim kaygısı sergileyen katılımcıların\%45,45'i daha önce yurt dışına çıktıklarını ifade etmiştir. Aynı gruptaki bireylerin \%54,54'üise daha önce yurt dışında bulunmadıklarını belirtmiştir.

- Orta düzey kültürlerarası iletişim kaygısı gösteren öğrencilerin\%89,18'i yurt dışında bulunmuşken, \%10,81'i bulunmamıştır.

- Yüksek kültürlerarası iletişim kaygısı sergileyen katılımcıların \%69,09‘u yurt dışı tecrübesine sahipken, \%22,97'si sahip değildir.

Yukarıdaki verilere göre katılımcıların yurt dışı tecrübesi ile kültürlerarası iletişim kaygısı arasında anlamlı bir ilişki görülmemektedir.

Sonuç olarak; yüksek kültürlerarası iletişim kaygısının yabancı dil öğretimde bir engel oluşturduğu ifade edilebilir. Şayet doğru yaklaşımlar benimsenirse bu engelin etkisi azaltılabilir. 
Bunun dışında cinsiyet gibi diğer etmenlerin de bu kaygı düzeyi üzerindeki muhtemel etkisi hesaba katılmalıdır.

\section{Kaynakça}

Arabski, J., \& Wojtaszek, A. (2011). Aspects of Culture in Second Language Acquisiton and Foreign Language Learning. Springer-Verlag. https://doi.org/10.1007/978-3-642-20201-8

Ay, E., Kavuran, E., \& Türkoğlu, N. (2018). Intercultural Communication Apprehension Scale (prica): validity and reliability study in Turkish. International journal of caring science, 12(11), 1638-1646.

Barna, L. M. (1998). Stumbling blocks in intercultural communication. R. Porter \& L. Samovar (Eds.), Intercultural communication: A reader (pp. 337-346). Wadsworth Publishing Company.

Bayat, B. (2014). Uygulamalı Sosyal Bilim Araştırmalarında Ölçme, Ölçekler ve "Likert" Ölçek Kurma Tekniği. Gazi Üniversitesi İktisadi ve İdari Bilimler Fakültesi Dergisi , 16(3) , 1-24 . http://dergipark.org.tr/tr/pub/gaziuiibfd/issue/28309/300829.

https://doi.org/ 10.26745/gaziuiibfd.300852

Bennett, Janet M. (2009). Cultivating Intercultural Competence: A Process Perspective.” Deardoff, Darla K. (Eds.) The SAGE Handbook of Intercultural Competence. Thousand Oaks, 121140.

Bennett, Janet M. (1993). Towards ethnorelativism: A developmental model of intercultural sensitivity. R. M. Paige (Eds.), Education for the intercultural experience (2nd ed., pp. 2171). Intercultural Press.

Büyüköztürk, Ş. (2005). Anket Geliştirme. Türk Eğitim Bilimleri Dergisi, 3(2), 133-151. https://Dergipark.Org.Tr/En/Pub/Tebd/İssue/26124/275190

Byram, M. (1997). Teaching and Assessing Intercultural Communicative Competence. Multilingual Matters.

Byram, M. (2008). From Foreign Language Education to Education from Intercultural Essays and Reflections. Multilingual Matters.

Canale, M., \& M. Swain. (1980). Theoretical Bases of Communicative Approaches to Second Language Teaching and Testing. Applied Competence. Multilingual Matters. https://doi.org/10.1093/applin/1.1.1

Chomsky, N. (1957). Syntactic structures. The Hague.

Çiloğlan, F., \& Bardakçı, M. (2019). The relationship between intercultural sensitivity and English language achievement. Journal of Language and Linguistic Studies, 15(3), 1204-1214. https://doi.org/10.17263/jlls.631563

Deardorff, Darla K. (2006). Identification and assessment of intercultural competence as a student outcome of internationalization. Journal of Studies in International Education, 10(3), 24166.

Deardorff, Darla K. (2009). Handbook of Intercultural Competence. Sage Publications Inc. 
Ekiz, D. (2013). Bilimsel Araştırma Yöntemleri. Anı.

Fantini, Alvino E. (1991). Bilingualism. Exploring Language and Culture. M. Lilliam \& D. Georges (Eds.), Language, Culture and Cognition. A Collection of Studies in First and Second Language Acquisition (pp. 110-119). Multilingual Matters. https://doi.org/10.1075/lplp.18.2.17

Gardner, G. H. (1962). Cross-cultural communication. Journal of Social Psychology 6(58), 241256.

Gönül, Ş. S. (2007). Intercultural Communicative Competence: The Assessment of a Turkish Set for Foreign Adult Learners. Doktora Tezi, Hacettepe University Graduate School of Social Sciences, pp.4-5.

Gudykunst, W. B. (1993). Toward a theory of effective interpersonal and intergroup communication: An anxiety/uncertainty management (AUM) perspective. R. L. Wiseman \& J. Koester (Eds.), International and intercultural communication annual (pp.33-71). Sage Publications, Inc. https://doi.org/10.1002/9781118783665.ieicc0007

Hamamc1, Z. \& Hamamc1, E. (2015). Yabancı Dil Öğreniminde Kayg1 Üzerine Bir Alan Yazın Taramas1, Ë̆itim ve Öğretim Araştırmaları Dergisi, 4(4), 374-383.

Hymes, D. (1962). The ethnography of speaking. T. Gladwin \& W. Sturtevant (Eds.), Anthropology and Human Behavior. Anthropological Society of Washington.

Hymes, D. H. (1972). On Communicative Competence. J. B. Pride, \& J. Holmes (Eds.), Sociolinguistics: Selected Readings (pp. 269-293). Penguin.

Jackson, J. (2012). The Routledge Handbook of Language and Intercultural Communication. Routledge.

Jandt, F. (2018). Intercultural Communication. Identities in a Global Community. SAGE.

Jiang, W. (2000). The Relationship Between Culture and Language. ELT Journal. 54(4), 328-334.

Karasar, N. (2003). Bilimsel Araştırma Yöntemleri. Nobel Yayınları.

Kartarı, A. (2014). Kültür, Farklıllk ve İletişim. İletişim Yayınları.

Kramsch, C. (1993). Context and culture in language teaching. Oxford University Press.

Kramsch, C. (1995). The Cultural Component of Language Teaching, Language, Culture and Curriculum, 8 (12), 83-92. https://doi.org/10.1080/07908319509525192

Liddicoat, A. J. (2002). Static and dynamic views of culture and intercultural language acquisition. Babel, 36(3), 4-11, 37.

Liddicoat, A.J., Papademetre, L., Scarino, A., \& Kohler, M. (2003). Report on intercultural language learning. Linguistics, 1 (1). 1-47.

Lustig, Myron W., \& Koester J. (2008). Intercultural competence (Intercultural communication across the cultures). Pearson.

Neuliep, J. \& McCroskey, J. (1997). The development of intercultural and interethnic communication apprehension scales. Communication Research Reports, 14(2), 145-156. https://doi.org/10.1080/08824099709388656

Samovar, L.A., Porter, R.E. \& McDaniel, E.R. (2010) Communication between cultures. Wadsworth Cengage Learning. 
Rafek, M., Ramli, N., Iksan, H., Harith, N. \& Abas, A. (2014). Gender and Language: Communication Apprehension in Second Language Learning. Procedia - Social and Behavioral $\quad$ Sciences. 123. https://doi.org/10.1016/j.sbspro.2014.01.1401

Van Ek, J. (1986). Objectives for Foreign Language Learning. Council of Europe. 